\title{
'Mindfulness' in an Era of Acceleration
}

\author{
Bert Olivier
}

\section{Abstract}

Imagine Descartes in the $17^{\text {th }}$ century, penning his famous Meditations, trying desperately to concentrate on the properties of a piece of wax, in-between checking his email on his smartphone, or laptop, or iPad. Distraction overload to the nth degree! Unavoidably this relates to negotiating the mass of technologically mediated distractions coming at us from all directions today, contributing to the increasing acceleration of our lives. The paper focuses on the work of Paul Virilio on acceleration and 'grey ecology', as well as on that of Sherry Turkle and Bernard Stiegler on the obsessive use of technical devices, to be able to grasp the character of contemporary social life. Few people are prepared to embark on disciplined Zen-Buddhist meditation, but the stresses accompanying the accelerated life which is a function of the technological revolution we are living through have given rise to resistance through art, and have made a growing number of people receptive to what is known as mindfulness-based stress reduction (MBSR). The paper therefore examines this as a response to the pressures of the present era, and, by way of returning to Freud's work in Totem and Taboo, aims to demonstrate that in the accelerated life of today, there are signs of a kind of 'quasi-mass-neurosis' because of the link between advanced technology and socialisation. Is it farfetched to see in the compulsive checking for messages on smartphones or laptops a persistence of what Freud called a 'compulsion neurosis', today better known as OCD, or obsessive-compulsive disorder? Although it is doubtful whether everyone who compulsively checks for text messages or the like would qualify for being clinically diagnosed with $\mathrm{OCD}$, the behavioural resemblance is striking. A compulsion neurosis is driven by an unconscious belief that, unless one repeats a certain action over and over - here, the technologically mediated one of 'staying in touch' - something 'terrible' will befall one. The link between this behaviour involving smartphone 'addiction' 


\section{Bert Olivier}

(Turkle, Stiegler), 'grey ecology' (Virilio) and the prospect of a psychoanalytical reconfiguration of contemporary subjects' relationship with power is examined in this paper.

Keywords: acceleration, compulsion neurosis, fetishism, grey ecology, Freud, images, mindfulness, smartphones

We live in an era of unprecedented 'acceleration' at virtually every level of human existence - those of communicating with one another, of working (more productivity routinely being expected of employees, and in a certain sense never being 'off duty', given the phenomenon of 24-hour availability through smartphone communications technology), of investing (an investment can be moved instantaneously by the tap of a finger), and of travelling (the speed of travel constantly tends to be increased, whether by road, air, water or rail), to mention only some. The most consequential sphere of acceleration, however, is probably that of the media, including television and all the electronic means by which the internet is accessed. Paul Virilio, probably the most significant thinker on questions concerning 'acceleration' in the era of ubiquitous imagesaturation, expresses the links among these phenomena in succinct terms in an interview with John Armitage (2001: 119):

What I'm trying to show is the really powerful character of the images that are produced everywhere around us and that no one is analysing. Because images have become munitions. Their delivery and impact have the same speeds as the impact of a bullet. The arms [weapons; $\mathrm{BO}$ ] of the future will much more resemble a TV than a mortar.

An architect and philosopher, Virilio's work has transformed the way people think about the relationship between speed (or acceleration), visuality (or visual culture), technology, the military, and the distinctive mode of existence of people in the early $21^{\text {st }}$ century. Few people probably ever think of the ubiquitous images rushing at them from all directions as weapons, but it is not that difficult to grasp, if one considers that the 'charge' of such images is usually information which is not that innocent. They are usually either branded images, promoting a branded product, or images of so-called 'celebrities', who 
are 'human brands' - in both cases clearly images heavily invested with certain interests - or they are news images aimed at influencing the way viewers think and act, and so on. In short, media images are ideologically-charged 'bullets' of sorts, and Virilio is one of the few philosophers in the world making this explicit. Another one is Bernard Stiegler, who is just as uncompromising as Virilio, extending acceleration to technology in its entirety. In States of Shock (2015: location 6204) he observes that: 'Technics and technology are always systems and devices of acceleration - and thus are always, and for this very reason, also weapons'. It is no accident that these thinkers' intellectual work converges on speed and technology, and that there are indications that this is closely related to specific human behaviour, as I shall demonstrate below.

In Virilio and Visual Culture, John Armitage and Ryan Bishop (the editors) sum up Virilio's work as follows (pp. 1 and 2):

Paul Virilio's major contribution to contemporary European thought has been to demonstrate that questions of visual culture are not only academic and cultural, aesthetic, historical, critical, philosophical and anthropological questions but also extremely important political questions .... Virilio reminds us that the battlefield [meant literally; $\mathrm{BO}$ ] is primarily a visual and sensory domain: perception as aiming and targeting, hiding and uncovering, and that urban centres result from paths of movement and means of defence, all of which responds to and alters the visual field. The visual domain, in Virilio's theoretical work, no matter how it manifests itself, is always concerned with movement, speed, time, the built environment, technology and their complex interactions, resulting in the constantly increasing militarisation of all aspects of daily life.

If the connection between the visual field and 'militarisation' seems dubious, consider the following. Many of the technologies that already affect our lives significantly have a military origin - the internet, to begin with, which started as a military invention called DARPANET, before it was opened up to commercialisation and private communications. In a recent article, Rob Lever (2018) foregrounds some of these military links, although he does not mention the military by name, where he quotes the founder of Future Today, Amy Webb, as commenting on the future of smartphones, to the effect that: 
2018 'marks the beginning of the end of traditional smartphones' and [she] sees a transition to a new era of computing and connected devices based on voice, gesture and touch.

'The transition from smartphones to smart wearables and invisible interfaces - earbuds that have biometric sensors and speakers; rings and bracelets that sense motion; smart glasses that record and display information-will forever change how we experience the physical world', Webb writes.

This confirms just how pertinent Virilio's work (together with that of other thinkers on technology, like Gilbert Germain, Sherry Turkle, Jean Baudrillard, Manuel Castells and Bernard Stiegler) is for understanding the era we live in. What interests me is the psychological effect of the phenomena highlighted by Virilio, and what they imply with regard to what might be termed an 'anthropology of the present'. In all of this Virilio highlights the central function of speed or acceleration, which does not leave human existence untouched, of course. In The Information Bomb (Virilio 2005: 66-67), already, he wrote about the shrinking of time (that is, the acceleration of our lives' tempo) that accompanied the invention and use of mobile phones, which enable employers to 'abolish the distinction between working hours and private life for their employees...'. Just how far-reaching such developments really are in psychological (and psycho-somatic) terms is evident from a recent article by Jake Kwon and Alexandra Field (2018) on South Koreans 'working themselves to death'. Referring to a Korean man who died suddenly at work for no ascertainable reason (except for the unbearable acceleration of his life, one might surmise in the light of Virilio's research), they write:

Chae Soo-hong worked at a food supplier specializing in jangjorim, a popular Korean side dish of beef cooked in soy sauce. His primary duty was to make sure production was up to standard and on time.

During the week he would travel to the company's factories and oversee production. On Saturdays, he went to the main office to do paperwork. Even after coming home from work, his job wasn't done: though it wasn't his explicit duty, he'd often spend the evening fielding calls from factory employees, mostly foreign migrant workers who 
needed help adjusting to life in South Korea.

Virilio is betting on technological changes in speed and acceleration continuing to affect human lives, usually without people even being aware of it. In a disturbing paper titled 'The illusions of zero time' (2013) he analyses the relation between technologically mediated and produced televisual images and the 'last horizon of visibility' (Virilio 2013: 28), which is also an immovable limit, namely the speed of light. The overall effect of this - as well as of many other related phenomena, such as virtual-reality helmets and simulators - is what Virilio calls the 'cyberneticisation of geophysical space'. In concrete terms, this means that the 'optical depth of the human environment is reduced' (2013: 28) or that there is a disconnect between the time-space of television viewers' bodies (at the time of their viewing of television programmes) and the 'frame of the screen' or 'televisual horizon' (2013: 29). If this seems innocuous, consider Virilio's phenomenologically oriented question (2013: 30):

Isn't the wrong that telecommunications technologies are committing here, by isolating the present from its 'here and now' in favour of a communicative elsewhere that is no longer the site of our concrete presence in the world, but merely of a discrete and intermittent telepresence? The real time of telecommunications does not stand opposed, then, as is generally claimed, simply to the past - to 'the recording' - but to the present and its very nowness - an optical switching between the real and the figurative that refers back to the physical observer present here and now, the only persistent factor in an illusion in which the body of the witness becomes the sole element of stability within a virtualised environment.

The reasons for Virilio's concern may elude one unless one recalls the character of one's spatiotemporal 'life-world', which contrasts starkly with the character of televisual images as described by Virilio - images which have, ironically, been embedded in our life-world, and perhaps to our detriment.

\section{'Grey Ecology' and Resistance through Art to Hyper- acceleration}

Against this backdrop - of Virilio's diagnosis of the present as a time where 
speed threatens to disrupt one's ordinary mode of being-in-the-world - it is not surprising that there have been signs of resistance to the mindless, or perhaps rather 'body-less', adaptation to an inhuman, constantly accelerating way of living. For Virilio, 'grey ecology' marks a different kind of ecology compared to 'green ecology' - while the latter pertains to nature and the integrity or disintegration of her ecosystems, 'grey ecology' pertains to the relationship between space and time in the present era of hyper-acceleration. As he puts it in Crepuscular Dawn, in answer to a question by Sylvere Lotringer in an extended interview (Virilio \& Lotringer 2002: 63):

We are confronted with the phenomenon of confinement. Michel Foucault analyzed the great imprisonment in the eighteenth century with the closing of asylums, the disciplinary politics of the Great Enclosure. But the Great Enclosure isn't behind us with Bentham's Panopticon, it is ahead of us with globalization. And I would say that this is the grey ecology. Besides the ecology of substances, the green ecology, there is an ecology of distances. The telluric contraction of distances, the pollution of distances, as I call it - not the pollution of nature but the pollution of distances in nature - this will make the Earth uninhabitable. People will suffer from claustrophobia on the Earth, in the immensity of the planet.

The irony encapsulated in the last sentence of this excerpt highlights the clash between the 'space-time' of everyday experience as it was before the advent of what Manuel Castells (2010) calls the 'network society', characterised by the novel experiential modes of the 'space of flows' and 'timeless time', where particularly the latter resonates with Virilio's notion of hyper-acceleration, given its constant approximation of an undiluted present. Corroborating Virilio's insights, Castells (2010: 460-499) adduces instances of the tendency, in our culture, to cancel time out altogether, even if this limit cannot ever be fully actualised. Not that there are no avenues of resistance to the consequences of acceleration. For example, practising artist, Joy Garnett (2013: 37), highlights the significance of this in terms of 'grey ecology':

Pondering this real-time enslavement to the closure of distances coupled with the prospect of collectively experienced disasters [what Virilio conceives of as the unavoidable 'catastrophic accident' of the 
present; $\mathrm{BO}$ ], Virilio enjoins us to search for a corrective. This is the significance of a 'grey ecology', his poetic term for processes that engender alternatives to what he has identified as our current apocalyptic condition, one in which we are forced to deny anything that does not take place in an absolute present...

Of course, one knows that this 'absolute present' (Castells's 'timeless time') is a newly normative temporal fiction (because it cannot ever be fully actualised, only approximated) that subordinates other, older modes of time-awareness (notably 'clock time' or 'sequential time'; Castells 2010: 463), but one that increasingly governs the way people perceive the world. When one visits international news websites such as CNN International, BBC International, Al Jazeera, RT Today or France 24, invariably our eyes are drawn to the 'newsline' where the latest news items scroll past uninterruptedly, or to the 'Breaking News' column, both of which are the markers of the 'absolute present' Garnett alludes to. Needless to emphasise, this (typically postmodern or 'schizophrenic'; Jameson 1983: 119) valorisation of the 'perpetual present' as the ontological locus of being or existence, functions to disrupt the threedimensional or sequential (past/present/future) time-awareness of people that has, since time immemorial, provided them with a temporal spectrum of orientation, as Heidegger has demonstrated in exemplary fashion in his monumental Being and Time (1978), where he argues for the primacy of time as ontological category for the understanding of Dasein or being-human.

Returning to what Virilio calls 'grey ecology', it is worth repeating that it is something that is peculiar to the accelerated world we live in today, in the early 21 st century, and has to do with the overcoming of distance, of slowness, and of a mode of living that allows you to 'stop and smell the daisies', as it were. In fact, it is the ecology of distances, but in a peculiar way, as one can gather from what Virilio says in response to a question by Sylvere Lotringer (Virilio \& Lotringer 2002: 79):

For a long time now, I have had the feeling that we are heading toward an unbearable way of life. I'll explain. The body proper of our habitat has become not only unhealthy due to the pollution of the substances that make it up - this is green ecology — but soon uninhabitable, or almost, due to the sudden pollution of temporal distances, these intervals that threaten the world's geophysics. The world of green 
ecology is unhealthy, and the world of grey ecology is becoming uninhabitable. Because it's too small. And because after a while, this interactivity becomes unbearable.

In other words, what Virilio is talking about (contrary to what might seem to be the case) is the shrinking of spatial distance because of the overcoming of 'temporal distances'. And for him this leads, ultimately, to the world becoming uninhabitable because people are crowding one another, increasingly, and unbearably, through all the modes of interactivity that advanced electronic means of communication make possible. But there are indeed ways and means to resist the effects of this 'grey ecology', such as artistic practices which are actually engendered by itself as 'alternatives' or 'correctives' to it. One example of this is the work of Joy Garnett (referred to earlier), both as an artist and as a thinker. In 'Towards a new ecology of time' (2013: 37-45) she sets out a programme of painting that has a modest aim (2013: 38-39):

... how might the art of painting, despite its late, great, failed attempt at transcending representation and hence the limitations of flesh, insert itself now, and perhaps disrupt the hyper-accelerated, dematerialised electronic surfaces and information clouds that dominate our age? Can the outmoded notion of a gestural painting become useful in unexpected ways, as we attempt to make sense of our runaway will to accelerate beyond the boundaries of the human body and its ecosystems? Moreover, can we harness this renewed understanding of the painted physical gesture in a way that will point us to the humble preservation of what is left in our culture that remains fully human...?

She goes on to suggest that Virilio's work on 'grey ecology' calls for a 'renewal'; one that, recognising the 'dogma of acceleration', will turn to the 'poetics' of ephemeral processes in a manner that acknowledges that a sustainable culture needs such delicate things. Such ephemera would include the 'slowness and imperfection of human nature and the animal organism' (2013: 40) - something that painting is capable of capturing in inimitable ways. Her own painting sets out to appropriate digital images of, among others, a military, scientific or documentary kind and 'remake' them through painting to be commensurate with natural human needs (2013: 43). In short, Garnett employs her art as a vehicle to combat the deleterious effects of ubiquitous 
'acceleration', in this way calling one back to a way of living that is consonant with human needs and desire(s). There are also other contemporary phenomena which join forces with Garnett's art and Virilio's philosophy to 'return' one in the sense of Julia Kristeva's (2000: 1) 'revolt', which means, among other things, to 'return' to oneself - to such a mode of living. One of these is what is today known as 'mindfulness'.

\section{'Mindfulness' as Response to an Accelerated Life}

In the $17^{\text {th }}$ century Descartes, the 'father' of modern philosophy, distinguished between 'intuition' (the concentrated focusing of the mind on one idea) and 'deduction' (the logical process of moving from one intuition to the next by inference). Both were regarded by him as being essential for the philosophical 'direction' of the mind (Descartes 1911a: 7-8). The fact that Descartes could sit near a warm stove in Holland, concentrating meditatively on the phenomenon of doubting something, with a view to finding something rocksolid in his reasoning to treat as an indubitable foundation of thought, was possible in 17th-century Europe, because distractions were far fewer than they are today. Imagine Descartes, trying desperately to concentrate on the properties of a piece of wax, which he did in the writing of his famous Meditations on First Philosophy (Descartes 1911), in-between checking his email on his smartphone, or laptop, or iPad, or - soon to come - his smartwatch, or Google-glasses! Distraction overload to the nth degree. Or imagine Kant trying to focus on some of the more demanding passages in the writing of his Critique of Pure Reason of 1781 (Kant 1998) with about a dozen or so emails to answer at the back of his mind. It is probably true to say, however, that with new technology comes the need to adapt one's thinking or writing to new demands, which Descartes or Kant would probably have done if they had lived today, but with unpredictable outcomes.

But that would mean negotiating the Scylla and Charybdis (multiplied by 100) of technologically mediated distractions coming at us from all directions today, like miniature Kamikaze pilots bent on somehow entering our minds to deposit their informational payload there. This is precisely what everyone who values meditative or contemplative engagement with things, phenomena, ideas, and so on, has to do all the time when surrounded by all these infiltrators of the age of technocracy. As every meditation-aficionado knows - whether it is in the philosophical sense, or the yoga sense, or the 
Zen-Buddhist sense - meditation cannot proceed unless you 'empty' your mind of all needless distractions, focusing 'mind-fully' on every action, such as breathing slowly and regularly, bathing in a relaxed manner, doing housework slowly and rhythmically, and maintaining a tranquil silence (Thich Nhat Hanh 1987: 27-31). In Zen one might say that the ultimate goal (which is not really a 'goal' at all) is to surround yourself with 'nothing', or pure emptiness, because paradoxically, it is only by contemplating 'nothing' that you will find 'yourself' - a precept that corresponds, perhaps surprisingly, with that of the subject of the symbolic register in Lacan's theory of the subject the je or 'I' which, unlike the subject of the imaginary register, the moi, or 'me', escapes all objectification, at least at the unconscious level of the 'enunciation' (as opposed to the conscious 'statement') as is also the case with the subject of the 'real', which is foreclosed and, from the perspective of language and of iconicity, 'nothing' (Evans 1996: 56, 58). Few people are prepared to embark on that road of disciplined meditation, but the stresses brought on by the accelerated life accompanying the technological revolution we are living through have been enough to make a growing number of people receptive to what is now known as 'mindfulness-based stress reduction' (MBSR).

A few years ago this phenomenon found its way into Time magazine, with an article by Kate Pickert (2014) titled 'The art of being mindful', and subtitled 'Finding peace in a stressed-out, digitally dependent culture may just be a matter of thinking differently'. Reading the piece one soon learns that 'mindfulness' - a notion inseparable from Buddhist meditation practices of 'engagement' (Thich Nhat Hanh 1987) - here does not mean having a mind crammed full of distracting stimuli competing for your attention, but exactly the opposite, namely learning to concentrate on one experience at a time, to be able to rediscover what it is all about, like eating a raisin. Significantly, the first two pages of the article consist of a photograph of about a dozen people walking around on a green expanse of grass, with trees and buildings in the background, with the caption, 'Students in a mindfulness class demonstrate a technique called aimless wandering'. This just about says it all about the arguably disoriented time we live in - that people have to take 'classes' in 'mindfulness' to (re-) learn that it is all right to do something like walking around in an 'aimless' manner, that is (I assume), without having anything else but walking in mind. What caused us to 'unlearn' it in the first place? Pickert, who attended a MBSR course, answers this question as follows (2014: 34): 
Although I signed up to learn what mindfulness was all about, I had my own stressors I hoped the course might alleviate. As a working parent of a toddler, I found life in my household increasingly hectic. And like so many, I am hyper-connected. I have a personal iPhone and a BlackBerry for work, along with a desktop computer at the office and a laptop and iPad at home. It's rare that I let an hour go by without looking at a screen. Powering down the internal urge to keep in constant touch with the outside world is not easy.

In this description of the familiar situation in which many individuals find themselves today, Pickert touches upon something highly suggestive: '...the internal urge to keep in constant touch with the outside world ...' She is not alone in this respect - by all accounts most smartphone-carrying people in the world today frequently, if not constantly, check their devices for new messages on Whatsapp, Twitter, and other social media platforms. This is something that has attracted the attention of several prominent researchers. Sherry Turkle, for example, pays incisive attention to this phenomenon. In Reclaiming Conversation (2015: 42-44), where she advocates the (psychoanalytical) 'talking cure' in the guise of conversation as preferred approach to the ills of hyper-connectedness, she elaborates on the difficulties one faces in this regard. One of the startling findings of her research is that one of the personal capacities that many people claim with pride, namely 'multitasking', may actually be a function of hyper-connectedness, and judging by responses from research subjects, seems to be standing in the way of individuals' ability 'to focus on one thing' (as required by 'mindfulness'), such as conversation (2015: 42). Some actually see conversation as an obstacle to multitasking (2015: 43).

For Turkle (2015: 43), it is not productive of dealing with the problems accompanying the media-saturated lives we lead to think of being 'addicted to multitasking', because it is not a matter of simply jettisoning one's smartphone or tablet - they 'are part of our media ecology'. Addiction requires ditching the substance one is addicted to; in the present situation it seems to be rather a matter of being 'vulnerable' to what technology offers. But how does one become 'less vulnerable' (Turkle 2015: 43)? Clearly, what has been discussed, above, as 'mindfulness-based stress reduction' is one possible strategy or practice, and as I shall argue below, psychoanalysis offers other ways of dealing with such vulnerabilities. Predictably, in the present context of a technology-saturated world - where the majority of people cannot step back 


\section{Bert Olivier}

from their immersion in technology, to be able to 'think about technology' from a different perspective (Germain 2017: xi-xii) - the first option for addressing the pathologies of a 'technologically accelerated world' seems to be another technological 'solution' to an increasingly problematical situation. Turkle characterises this as follows (2015: 44):

I meet with an inventor who observes that when people engage with smartphones, they are compelled into a new kind of vigilant behavior. 'They want to make sure they're not missing anything,' he says, so they keep interacting with their devices.' He makes this intriguing suggestion: 'What if we designed a smartphone interface that made it easy for us to do a specific task (such as messaging a friend or family member) and then, instead of encouraging us to stay connected as long as possible, would encourage us to disengage? The interface would be designed to reduce our usage, and make spending more time on our phone a deliberate action.' The point is not to make connection impossible or difficult. But it should demand intention; it should not be something the system helps you slide into. He says, 'So instead of a phone that keeps us mesmerized, we may want to build a phone that lets us attend to our business and then gradually releases us because that is what is best for us.'

The explicit suggestion by the inventor in this excerpt, that it be left to 'smart' technical devices to 'decide' on behalf of human beings, is revealing in more than one respect, which foregrounds another possible aspect of 'mindfulness', albeit not in the sense specified earlier. This has to do with the phenomenon, highlighted by Bernard Stiegler (2010: 35), that smartphones and other electronic 'mnemo-technical' devices seem to be taking over human capacities such as memory and knowing, and this at the behest of humans themselves. In this context one might want to insist on the ineradicable ability of human subjects, to be 'mindful' themselves (even if this ability seems to be forced into a condition of dormancy under present, techno-saturated circumstances), in the sense of deciding to keep technology at arm's length when excessive reliance on it leads to quasi-pathological behaviour (more on this below). What the inventor in this excerpt alludes to, namely smartphone-users' tendency, to ensure that 'they're not missing anything' corresponds to a familiar colloquial expression that even has its own acronym, to wit, FOMO - 'fear of missing 
out', which (by all accounts) fits smartphone users, generally speaking, like a glove.

\section{Technology and the 'Proletarianisation' of Users}

What the vast majority of people in our 'hyper-consumerist, drive-based and addictogenic society' (Stiegler 2015: location 290) do not realise, is that the technical gadgets that provide them with the 'freedom' to 'shop till they drop' (as the saying goes), are in the service of a neoliberal economic system which systematically robs them of their knowledge (or 'know-how') and of their ability to live a creative life, let alone of theoretical knowledge - what Stiegler phrases as 'savoir-faire', 'savoir-vivre' and 'savoir théoriser' (Stiegler 2010: 30). The psychological, or to be more precise, psychopolitical, import of this situation is far-reaching, as Stiegler (2010: 28-36) has argued persuasively, highlighting what he calls the 'proletarianization' of consumers today, taking the process that Marx identified in the $19^{\text {th }}$ century (as 'proletarianization' of workers, who were stripped of their 'know-how' by machines; Stiegler 2010: $33,37-38$ ) to another level. Today, the loss of knowledge on the part of workers in the $19^{\text {th }}$ century has evolved to the point where it manifests itself as (Stiegler 2010: 39) ' $\ldots$ bringing into the process of proletarianization all those whose knowledge is absorbed by hypomnesic [that is, technically exacerbating memory; $\mathrm{BO}$ ] processes consisting not only in machines, but in apparatuses, expert systems, services, networks, and technological objects and systems of all kinds'.

The apparatuses alluded to here by Stiegler include smartphones, electronic tablets, laptops and desktop computers, that is, all the informationcommunicational devices one uses daily for work and leisure purposes. What may not be clear is the sense in which the use of such 'hypomnesic' devices is of psychopolitical significance. To be as succinct as possible, the large-scale use of these instruments for increasing the buying power of the public systematically replaces their own thinking and inventive capacities with preformatted templates for living, forcing them to adapt to 'whatever marketing devises'. 'And today', Stiegler (2015: location 4902-4913) continues, 'all this occurs with the help of the social and cognitive sciences - neuromarketing being the most advanced stage of this aspect of proletarianization'; even '...fundamental theoretical knowledge is proletarianized, that is, decoupled from theoretical activity...[W]hat is taught today, therefore, is increasingly a 
purely procedural technological knowledge, including in the faculty of sciences, at the expense of the historical and critical knowledge of the theories lying at the origin of these formalisms'. In other words, proletarianisation is not restricted to machine workers and consumers, but extends to intellectual work as well (Stiegler 2015: location 4970), and further serves the psychopolitical end of subverting the grounds of possible critique of the neoliberal system itself which, needless to point out, reinforces the latter by ostensibly ruling out any cogent alternatives, as Renate Salecl (2010) has remarked. In the idiom of Naomi Klein (2007) Stiegler (2015: location 5017) thinks of the effect of the systemic use, by capitalism, of technology and technical devices for expanding proletarianisation to consumers and scientists/intellectuals, as 'technological shock and its transformation by psychosocial individuation and by a state of philosophical shock' - where such individuation denotes the manner in which the widespread use of technical devices shapes individuals socio-psychologically, and 'philosophical shock' indexes a fundamental intellectual disorientation.

One may further note that, as long ago as in the 1940s, psychoanalytical thinker Erich Fromm anticipated the present state of affairs described above as one of (disorienting) 'acceleration' (Virilio), and of consumer 'proletarianization' (Stiegler) - in his classic work, Escape from Freedom (1965). Here he distinguishes among various 'mechanisms of escape', and singles out what he terms 'automaton conformity' as having 'the greatest social significance'. From what he writes in this regard it is easy to discern the resemblance between the situation he describes and the one obtaining today, where users vie with one another for (supposed) Facebook 'friends' and Twitter 'followers' (1965: 208-209):

This particular mechanism is the solution that the majority of normal individuals find in modern society. To put it briefly, the individual ceases to be himself; he adopts entirely the kind of personality offered to him by cultural patterns; and he therefore becomes exactly as all others are and as they expect him to be. The discrepancy between 'I' and the world disappears and with it the conscious fear of aloneness and powerlessness. This mechanism can be compared with the protective coloring some animals assume. They look so similar to their surroundings that they are hardly distinguishable from them. The person who gives up his individual self and becomes an automaton, 
identical with millions of other automatons around him, need not feel alone and anxious any more. But the price he pays, however, is high; it is the loss of his self.

The assumption that the 'normal' way of overcoming aloneness is to become an automaton contradicts one of the most widespread ideas concerning man in our culture. The majority of us are supposed to be individuals who are free to think, feel, act as they please. To be sure this is not only the general opinion on the subject of modern individualism, but also each individual sincerely believes that he is 'he' and that his thoughts, feelings, wishes are 'his.' Yet, although there are true individuals among us, this belief is an illusion in most cases and a dangerous one for that matter, as it blocks the removal of those conditions that are responsible for this state of affairs.

Needless to point out, Fromm's assessment of the state of affairs in 1940s American society resonates with that evoked by Virilio, Turkle and Stiegler concerning the contemporary world, although his phraseology centres on the 'self' instead of the effects of technology. Most pertinent for the present theme of 'mindfulness', however, is the question he raises about whether the thoughts and feelings one regards as one's 'own', really are one's own, or whether they have 'been induced from the outside' (Fromm 1965: 210). And his answer may be surprising (1965: 266):

We are proud that we are not subject to any external authority, that we are free to express our thoughts and feelings, and we take it for granted that this freedom almost automatically guarantees our individuality. The right to express our thoughts, however, means something only if we are able to have thoughts of our own; freedom from external authority is a lasting gain only if the inner psychological conditions are such that we are able to establish our own individuality.

The italicised sentence in this excerpt is crucial because, given the pervasiveness of electronically mediated communication today, it is much more likely than in Fromm's 1940s America that the 'thoughts' users articulate in Whatsapp messages, or via Twitter, are in an important sense 'not their own' (even if they are experienced as such by users), but have another provenance 
altogether. Broadly speaking the latter, I would suggest, is - as Stiegler (2015: location 4902-4913; 4970) suggests - 'whatever marketing devises', coupled with 'purely procedural technological knowledge', which militates against 'mindfulness' in the sense of a reflective, critical appropriation of the current 'overload' of information confronting users of technical devices. This is what 'proletarianisation' of consumers means in our contemporary society of 'acceleration'. It is against this background that the psychological implications of the phenomenon of 'mindfulness-based stress reduction' must be seen.

\section{Freud, Accelerated Living and Mindfulness}

In the light of the available evidence, that individuals in the early $21^{\text {st }}$ century are excessively dependent on their electronic communication-devices, the question that presents itself is this: Why do people yield compulsively to the urge to check their smartphones or tablets constantly for new messages or updates? It cannot merely be the case because they may have to respond to messages relating to their work - there is a multitude of teenagers who are constantly connected although they do not work. One is confronted by the possibility that this state of affairs arguably represents a mindset that is characteristic of an era where social behaviour has assumed the form of a quasimass-neurosis because of the link between advanced technology and socialisation. I wrote 'quasi'-mass-neurosis because in clinical-diagnostic terms I am not certain whether it would qualify as 'genuine' neurosis, but it nevertheless exhibits strikingly similar traits. In Totem and Taboo (1919), Freud wrote with great insight on the similarities between the lives of our primitive ancestors, or 'primitive peoples' in his words, and neurotics, and argued that '.. the study of the psychology of neurosis is important for the understanding of the development of culture' (1919: 122). It seems that this is as true today as it was a century ago, with the proviso that Freud's reference to 'primitive peoples' be understood strictly in non-racial terms, as a culturalhistorical observation, relating to the work of (cultural) anthropologists of the time. In other words, insofar as people of all cultures have been subject to cultural-historical development, historically they have all passed through the pre-modern (or, in another idiom, 'primitive') stage before entering that of the modern, and more recently what is sometimes called the postmodern. (As an aside, it should be noted that, arguably, the term 'culture' is preferable to that of 'race'; it is not one's 'race' that determines what you are as a person in 
essentialist terms, but the values embedded in one's culture, which are, in turn, embedded in your language. Moreover, anyone can question the cultural values in terms of which she or he was subjectivised - no one is a prisoner of their culture, unless they choose to be [Lacan 1977: 151-154; Foucault 1990: 84; Olivier 2012: 71-73].) This is important to keep in mind, because Freud's psychoanalytic theory, in its early as well as its mature form, is universally applicable to all human subjects, regardless of culture or race (Lacan 1977). This is the case with the category of the 'neurotic' as well.

Freud's (1919: 30-123, particularly 121-123) investigation of the primitive origins of taboo - a 'pre-religious' prohibition pertaining to certain actions, including touching the king, leader, chief, divine representative like a priest, or anything that belongs to him (or her), on pain of severe punishment, if not death, led him to noting the similarity between this and the 'touching phobia of neurotics' (Freud 1919: 45, 121). The latter refers to cases where someone has a deep-seated fear of touching something or someone, to the point of imposing all kinds of ludicrous penalties on themselves in case of doing so. For Freud, this similarity between taboo and neurosis uncovers the persistence in society of psychological traits (pertaining to unconscious wishes and fears) that originated much earlier in the history of humankind. The flip-side of these compulsively imposed penalties or expiations is the usually hidden element of phantasy on the part of neurotics. Hence, the following remark seems to me to go a long way towards theoretically explaining what has been characterised, above, as ‘quasi-mass-neurosis' (Freud 1919: 123):

... the asocial nature of the neurosis springs from its original tendency to flee from a dissatisfying reality to a more pleasurable world of phantasy. This real world which neurotics shun is dominated by the society of human beings and by the institutions created by them; the estrangement from reality is at the same time a withdrawal from human companionship.

This should be read together with another observation (Freud 1919: 143):

In every one of the neuroses it is not the reality of the experience but the reality of the thought which forms the basis for the symptom formation. 


\section{Bert Olivier}

It seems to me that these observations clarify the grounds for what was earlier referred to as FOMO, or 'fear of missing out' - noted by the inventor in conversation with Sherry Turkle (2015: 44) - as motivating factor for compulsive checking of smartphones. It is the thought of missing something, experienced subliminally as essential or crucial to their well-being, that impels individuals to do so. Phrased in terms of the gap between phantasy and the real world, they are motivated by the unconscious (pleasureable) phantasy of being the recipient of endless Facebook 'likes', or the equivalent of these, through the cyberspace of the internet - whether in Whatsapp, Twitter, e-mail, Facebook, or any other social media platform format - or, phrased negatively, the (unpleasureable) phantasy of not being the recipient of such messages. Moreover, this tendency, to have intermittent recourse to technical devices as portals to these social media, constitutes nothing less than (in Freud's words, quoted above), 'estrangement from reality [which] is at the same time a withdrawal from human companionship', paradoxical as it may seem. Sherry Turkle's (2015: 4-6) discussion of teachers' experiences relating to the inability of young pupils at an American school, to establish 'companionship' in the 'normal', face to face manner - preferring to text one another on their phones instead, and paying the price for this in the guise of a noticeable inability to show empathy to fellow pupils - is a stark reminder of the accuracy of Freud's insight in this regard.

In the light of the above, is it far-fetched to see in the compulsive checking for messages on smartphones, or tablets, or laptops, so neatly captured by Pickert (2014: 34), above - 'It's rare that I let an hour go by without looking at a screen' - a persistence of what Freud called a 'compulsion neurosis', today better known as OCD, or obsessive-compulsive disorder? A recent article (Kleinman 2018) not only confirms the pervasiveness of this behavioural phenomenon, but indicates a growing awareness among users, manufacturers and service providers that it should raise concern on the part of those who usually yield to this compulsion. Again, I doubt whether everyone who compulsively checks for text messages or the like would qualify for being diagnosed with OCD, but the behavioural resemblance is nonetheless striking. The point is that a compulsion neurosis is driven by an unconscious belief that, unless one repeats a certain action over and over - here, the technologically mediated one of 'staying in touch' because 'one does not want to miss out on anything' — something 'terrible' will befall one. This is why Freud (1919: 122) described a compulsion neurosis famously as 'a caricature of a religion', 
given the parallels between actions performed under the duress of religiously sanctioned prescriptions, and those carried out because of unconscious beliefs in retribution of some kind. Perhaps the emergence of 'mindfulness-based stress reduction' (MBSR) signals a welcome awareness that our very humanity depends on recovering from a kind of (quasi-) mass compulsion neurosis, and rediscovering what autonomy means - not being determined in our actions by things or gadgets in the technocratic world we inhabit, but determining for ourselves, sometimes by meditating on it, what is good for us as human beings.

\section{Conclusion: Psychoanalytically Reconfiguring One's Relationship with Technology}

From a psychoanalytic point of view, and keeping in mind Virilio's insights concerning 'acceleration' in the present era - something inextricably linked to neoliberal capitalist-justified technological advancements, as Stiegler (2015) has demonstrated - there is another path to overcoming these compulsions, however, namely that of the psychoanalytical clinic. Ian Parker (2011) has written persuasively about what is at stake for the analysand in the clinic, namely nothing less than the subject's relationship with 'power', or more concretely, those agencies that wield power in the extant world. In the present, 'neoliberal' era, as the name indicates, this is the hegemonic global economic system, which has become so intertwined with other spheres of society, such as the political, that it is virtually indistinguishable from these (Hardt \& Negri 2001; 2006; Castells 2010). One should not make the mistake to think that it is in the clinic where social, political or economic transformations can be causally effected, however, with presumably salutary consequences for subjects in society. On the contrary (Parker 2011: 196):

... the clinic can only operate as a place to unravel the ideological constitution of the individual subject if we insist on a radical disjuncttion between this site and the world. It is precisely because psychoanalysis breaks from everyday conversational procedures - because it refuses the 'relational' dimension of interaction and the attempt to forge an intersubjective space between speakers - that the analyst is able to provoke a questioning of what power is for the subject. 
Put differently, it is when a person is confronted with the difference between their daily immersion in the fantasy realm of imaginary 'likes' and 'dislikes', 'friending' and 'unfriending', on the one hand, and a 'part of the self that we do not know' (Parker 2011: 197), that the space opens up for a radical questioning, and perhaps transformation, of his or her relationship with hegemonic power (as metonymically represented by smartphones and social media sites today). How is this possible?

The key to understanding how the elusive, unknown (and unknowable) aspect of the subject can play the key role in the analysand's intimate 'revolution', lies, I believe, in grasping the status of technical gadgets as commodity 'fetishes', which metonymically index the capitalist system as a whole. It is no accident that Parker (2011: 86-89, 91, 94-95) regards the obsessional neurotic - discussed earlier in relation to Freud - as the exemplary capitalist subject. Insofar as the (obsessional) neurotic is 'normal', he or she may be understood in terms of a fantasy relationship with objects of desire embodied in what Lacan calls the objet petit a ('object a') - the 'little other object' that 'triggers' the subject's singular, but unconscious, desire - for example a painting, a song, a flower, a scent or aroma, which inexplicably awakens in one an unfathomable longing for 'something' (ultimately the profound 'lost object' or das Ding; Lacan 1992: 66-67; Evans 1996: 207). On the other hand, Parker (2011: 49) reminds one that, for the later Freud, 'perversion' amounted to the 'disavowal' or refusal of 'castration' - that is, a disavowal of 'lack' (or powerlessness) which, in Lacanian terms, is constitutive of the subject - and which manifests itself in the 'installation' of a fetish as a substitute for the mother's supposed 'phallus' (the signifier that guarantees the equivalence between 'mother' and 'father', that is, between what they represent). In other words, the fetish, in replacing the phallus (the symbolic representation of the fullness and power which will always elude the human subject, male or female), offers the assurance that, in Parker's (2011: 49) words, there is 'no lack in any subject'.

Hence, putting together the various parts of the argument, one may conclude that, in an accelerated world where one's time-awareness is severely dislocated (Virilio) and where mnemo-technical devices rob one of one's savoir-faire and savoir-vivre (Stiegler) - in this way giving rise to the phenomenon of 'mindfulness' as an attempt to regain some sense of orientation - we face a paradoxical situation. While it is 'normal' for subjects to maintain a fantasy-relation with their 'objects a' as pointers towards their (unconscious) 
singular desire, in a world where, by all accounts, a collective obsession with devices such as smartphones prevails (Turkle), this has apparently made way for a situation where perversity is the rule rather than the exception: the attachment on the part of consumers or users to their technical devices (in a sustained effort not to 'miss out' on anything) represents a condition of widespread fetishism, where the smartphone as fetish may be understood as signifier of putative fullness, that is, of perverse 'disavowal' of lack in subjects. Might one see in this a desperate, if unconscious, attempt to neutralise, or resist, the dislocating effects of pervasive acceleration? After all, 'disavowal' of the dislocating effects of the latter may take the form of denying non-pathological lack through the fetishisation of commodities like smartphones. Needless to emphasise, whether this is a defensible interpretation or not, insofar as societies worldwide are caught in a situation where 'speed' and smartphone addiction reign, with their deleterious psychological effects, of which mindfulness is a (would-be corrective) symptom, there is ample reason for concern.

\section{References}

Armitage, J. 2001. Virilio Live: Selected Interviews. London: Sage.

Armitage, J. \& R. Bishop (eds.). 2013. Virilio and Visual Culture. Edinburgh: Edinburgh University Press.

Castells, M. 2010. The Rise of the Network Society. Second edition. Oxford: Wiley-Blackwell.

Descartes, R. 1911. Meditations on First Philosophy. In The Philosophical Works of Descartes. Volume I. Haldane, E.S. \& G.R.T. Ross (trans.).

Cambridge: Cambridge University Press.

Descartes, R. 1911a. Rules for the Direction of the Mind. In The Philosophical

Works of Descartes. Volume I. Haldane, E.S. \& G.R.T. Ross (trans.).

Cambridge: Cambridge University Press.

Evans, D. 1996. An Introductory Dictionary of Lacanian Psychoanalysis. London: Routledge.

Foucault, M. 1990. Politics and Reason. In Kritzman, L.D. (ed.): Michel

Foucault: Politics, Philosophy, Culture. Interviews and Other Writings 1977-1984. New York: Routledge.

Freud, S. 1919. Totem and Taboo. London: Routledge.

Fromm, E. 1965. Escape from Freedom. New York: Avon Books. 
Garnett, J. 2013. Towards a New Ecology of Time. In Armitage, J. \& R. Bishop (eds.): Virilio and Visual Culture. Edinburgh: Edinburgh University Press.

Germain, G. 2017. Thinking about Technology. How the Technological Mind Misreads Reality. New York: Lexington Books.

Hardt, M. \& A. Negri 2001. Empire. Cambridge, Mass.: Harvard University Press. https://doi.org/10.2307/j.ctvjnrw54

Hardt, M. \& A. Negri 2006. Multitude. War and Democracy in the Age of Empire. New York: Penguin.

Heidegger, M. 1978. Being and Time. Macquarrie, J. \& E. Robinson (trans.). Oxford: Basil Blackwell.

Jameson, F. 1983. Postmodernism and Consumer Society. In Foster, H. (ed.):

The Anti-Aesthetic. Essays on Postmodern Culture. Port Townsend: Bay Press.

Kant, I. 1998. Critique of Pure Reason. Guyer, P. \& A.W. Wood (trans.).

Cambridge: Cambridge University Press.

https://doi.org/10.1017/CBO9780511804649

Klein, N. 2007. The Shock Doctrine: The Rise of Disaster Capitalism. London: Penguin.

Kleinman, Z. 2018. Are you Ready to Break Up with your Phone? BBC News (Technology), 26 December:

https://www.bbc.com/news/technology-46590880

(Accessed 27 December 2018.)

Kristeva, J. 2000. The Sense and Non-sense of Revolt: The Powers and Limits of Psychoanalysis. Volume I. Herman, J. (trans.). New York: Columbia University Press.

Kwon, J. \& A. Field 2018. South Koreans are Working Themselves to Death. Can they Get their Lives Back? 4 November.

https://edition.cnn.com/2018/11/04/asia/korea-working-hoursintl/index.html (Accessed 28 November 2018).

Lacan, J. 1977. The Agency of the Letter in the Unconscious or Reason since Freud. In Écrits: A Selection. Sheridan, A. (trans.). New York: W.W. Norton.

Lacan, J. 1992. The Ethics of Psychoanalysis. The Seminar of Jacques Lacan - Book VII. Porter, D. (trans.). New York: W.W. Norton.

Lever, R. 2018. After Conquering the World, Smartphone Faces Uncertain Future. Mail \& Guardian, 13 November. https://mg.co.za/article/2018- 


\section{1-13-after-conquering-the-world-smartphone-faces-uncertain-future}

(Accessed 28 November 2018).

Olivier, B. 2012. The 'Quasi-universality' of the Humanities. In Olivier, B. Intersecting Philosophical Planes - Philosophical Essays. Oxford: Peter Lang https://doi.org/10.3726/978-3-0353-0322-3

Parker, I. 2011. Lacanian Psychoanalysis. Revolutions in Subjectivity. London:

Routledge. https://doi.org/10.4324/9780203843918

Pickert, K. 2014. The Art of Being Mindful - Finding Peace in a Stressed-out,

Digitally Dependent Culture may Just be a Matter of Thinking

Differently. TIME magazine, February 3: 32 - 38.

Salecl, R. 2010. Choice. London: Profile Books.

Stiegler, B. 2010. For a New Critique of Political Economy. Ross, D. (trans.). Cambridge: Polity Press.

Stiegler, B. 2015. States of Shock: Stupidity and Knowledge in the $21^{\text {st }}$ Century. Ross, D. (trans.). Cambridge: Polity Press (Kindle edition).

Thich Nhat Hanh. 1987. The Miracle of Mindfulness. An Introduction to the Practice of Meditation. Mobi Ho (trans.). Boston: Beacon Press.

Turkle, S. 2015. Reclaiming Conversation: The Power of Talk in the Digital Age. New York: Penguin Press.

Virilio, P. \& S. Lotringer 2002. Crepuscular Dawn. Taormina, M. (trans.). New York: Semiotext(e).

Virilio, P. 2005. The Information Bomb. Turner, C. (trans.). London: Verso. Virilio, P. 2013. 'The illusions of zero time'. In Armitage, J. \& R. Bishop (eds.): Virilio and Visual Culture. Edinburgh: Edinburgh University Press.

Bert Olivier Extraordinary Professor Free State University bertzaza@yahoo.co.uk 